\title{
KARAKTER TOKOH UTAMA DALAM FILM ANIMASI POCOYO
}

\author{
Muhammad Farhan'), Wahda Ilham Saputra ${ }^{2)}$ \\ Program Studi Desain Komunikasi Visual \\ Fakultas Bahasa dan Seni Universitas Indraprasta PGRI \\ Jl. Nangka 58 Tanjung Barat, Jakarta Selatan, 12530 \\ mfarhan646@gmail.com
}

\begin{abstract}
Abstrak
Karakter dalam desain merupakan salah satu elemen penting di pembuatan sebuah cerita, seperti teks, gambar, karakter, bahkan animasi. Karakter yang baik bisa diukur dengan bagaimana karakter tersebut mempengaruhi seseorang lewat kisah yang diceritakan. Penelitian ini akan mengamati dan menganalisis karakter tokoh utama dari animasi Pocoyo. Pocoyo adalah animasi produksi Studio Zinkia Entertainment di negara Spanyol, dan animasi ini telah mendapat penghargaan sebagai karakter terbaik di festival El Chupete 2006.
\end{abstract}

Kata Kunci: karakter, tokoh utama, film, animasi

\begin{abstract}
Character in design is one of the important elements in making a story, such as text, images, characters, even animation. Good character can be measured by how the character affects someone through the story told. This study will observe and analyze the main character of the Pocoyo animation. Pocoyo is an animation produced by Studio Zinkia Entertainment in the country of Spain, and this animation has been awarded as the best character at the $2006 \mathrm{El}$ Chupete festival.
\end{abstract}

Keywords: characters, main characters, films, animations

Correspondence author: Name, E-mail, City, and Country

\section{PENDAHULUAN}

Sekarang ini animasi mengalami kemajuan seiring dengan berkembangnya teknologi sehingga sekarang proses pembuatannya menjadi mudah. Animasi tentunya memiliki nilai lebih dari sekedar gambar ilustrasi di atas media dua dimensi karena animasi dapat menampilkan satu gambar bahkan lebih yang seolah olah terlihat bergerak. Kemudahan seseorang ketika menikmati cerita dengan melihat tokoh dalam animasi bergerak seperti melihat kejadian yang dijadikan film, hal ini membuat animasi semakin diminati dan disukai. Karakter adalah hal penting dalam sebuah animasi yang memiliki daya tarik sendiri. Karakter tentu bisa menjadi faktor yang menyebabkan seseorang bersedia menonton sebuah animasi. Beberapa kata sifat seperti imut, lucu, keren, 
sederhana, hebat, dan lain-lain, dapat diungkapkan oleh seseorang ketika pertama kali melihat suatu karakter bahkan sampai setia untuk mengikuti perkembangan karakter dalam sebuah cerita. Kesan-kesan tersebut dapat terjadi akibat dari kesuksesan seorang desainer karakter yang memasukan sifat-sifat kepada karakter yang telah dibuatnya (Syahfitri, 2011).

Animasi Pocoyo produksi Zinkia Entertainment dan Granda International ini, merupakan salah satu animasi yang berhasil merebut perhatian penonton di seluruh dunia. Animasi Pocoyo, yang diciptakan oleh David Cantolla dan teman-temannya ini pertama kali dirilis tahun 2005 di negara Spanyol sebanyak 52 episode. Animasi ini memusatkan eksplorasi secara maksimal pada karakter-karakternya karena latar belakang tempat yang ada di animasi ini hanya berupa latar putih kosong. Tetapi walau hanya dengan itu Animasi Pocoyo berhasil memperoleh salah satu penghargaan bergengsi yaitu predikat Posisi Pertama kategori "Best Character" di festival anakanak "El Chupete 2006". Keberhasilan animasi Pocoyo dalam mengolah visual dari setiap karakter yang ada memberikan suasana yang berbeda dengan film animasi lainnya, hal ini merupakan sesuatu yang menarik untuk dibahas.

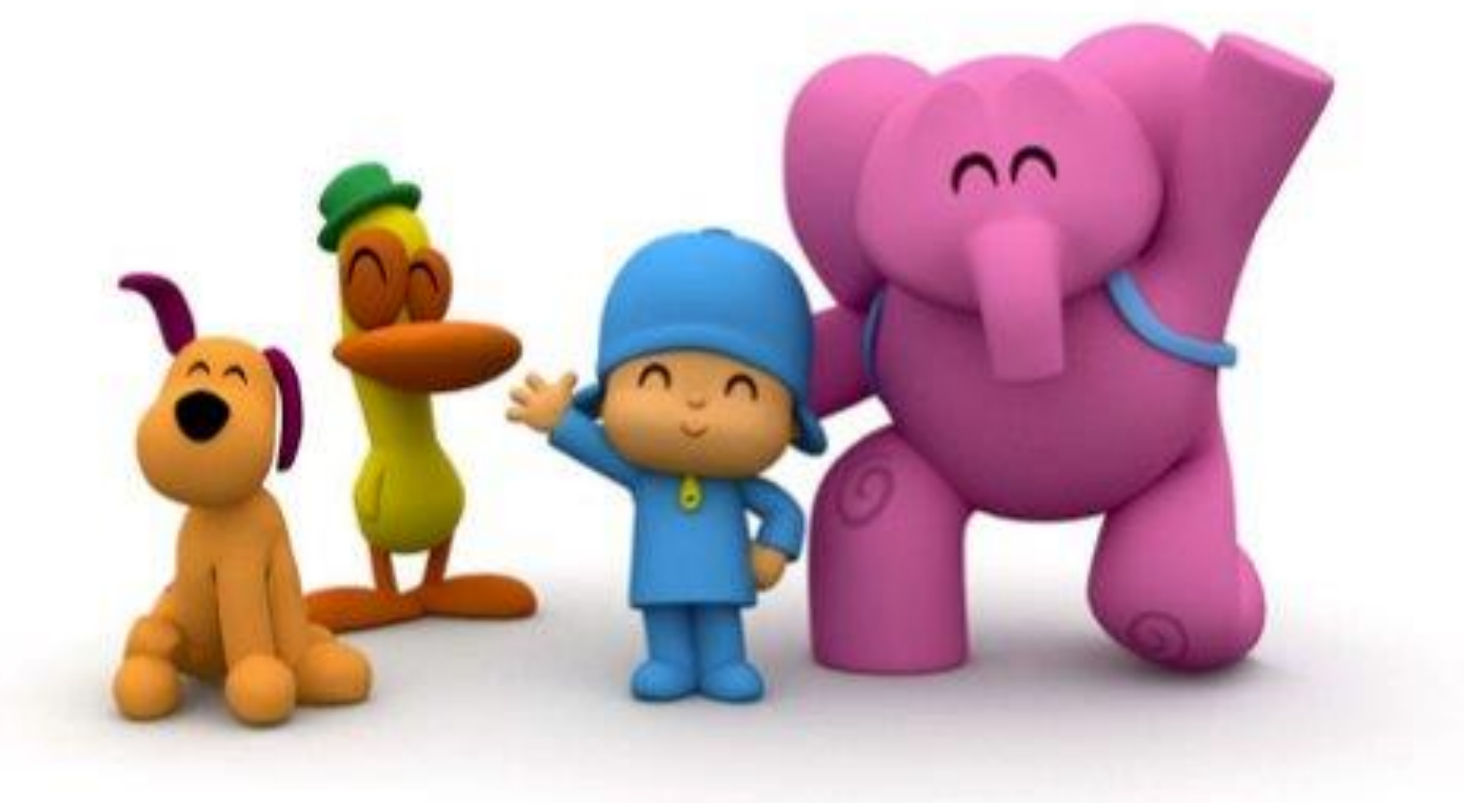

\author{
Gambar 1 Pocoyo \\ Sumber : http://pocoyo.blogs.com/
}

\title{
METODE PENELITIAN
}

Penulis menyusun artikel ini menggunakan metode kualitatif dengan teknik deskripti yaitu berusaha mendeskripsikan apa yang menjadi pengalaman peneliti melalui apa yang dilihat, didengar, dirasakan dan disimpulkan. Teknik pengumpulan data berupa studi pustaka, baik cetak seperti buku, maupun elektronik seperti blog, artikel, jurnal, dan sebagainya. Dari data yang penulis dapat penulis juga tidak hanya meng-copy-paste saja, tetapi penulis merangkum dan menganalisisnya.

\section{HASIL DAN PEMBAHASAN}

Menurut (Rachmat, 2017) pengertian karakter dalam film umumnya sama dengan pengertian karakter pada karya sastra, didalamnya memiliki unsur naratif dan penggambaran seorang karakter secara visual. Tokoh dalam cerita diatur untuk membangun relevansi, yakni suatu pencapaian ketika penonton memberi reaksi emotif tertentu seperti merasa akrab, simpati, empati, benci, antipati, atau berbagai reaksi afektif lainnya, dan pada sebuah cerita biasanya memiliki dua jenis karakter, yaitu karakter utama (protagonis) dan karakter pendukung karakter utama (dapat 
berupa antagonis atau figuran). Setiap karakter harus memiliki personaliti yang berbeda satu sama lain agar mudah dibedakan oleh para pembaca atau penonton. Unsur-unsur pembentuk personaliti.tersebut antara lain adalah sebagai berikut:

1. Ekspresi Wajah

Ekspresi wajah merupakan bentuk perwujudan dari emosi yang paling mudah dipahami ketika melihatnya. Ekspresi wajah bisa berubah tergantung pada situasi emosi yang dialami oleh karakter. Pada umumnya ekspresi dapat dilihat dari perubahan otot-otot pada alis, kelopak mata, dan gerakan mulut yang dapat memberikan nuansa emosi tertentu.

2. Penampilan dan Aksesoris

Persepsi pertama terhadap suatu karakter tentu tergantung pada penampilannya, khususnya pakaian dan aksesoris yang digunakan karakter tersebut. Cara berpakaiannya, model pakaiannya, serta benda-benda yang dimilikinya dapat mencerminkan kepribadian dari setiap karakter.

3. Bentuk dan Gestur Tubuh

Perbedaan bentuk tubuh pada setiap karakter mempengaruhi persepsi seseorang terhadap karakter tersebut. Seseorang yang terlihat gemuk, terlihat seperti tidak memiliki bakat dalam bidang olah raga, atau orang yang memiliki badan kecil terlihat lebih pintar. Emosi juga bisa dimunculkan lewat gerak-gerik tubuh atau gesture tubuh. Saat gembira, seseorang dapat terlihat sedang menari atau melakukan sesuatu sambil senyum dan bernyanyi.

4. Warna dan Komposisinya

Karakteristik dari sebuah karakter dapat ditimbulkan lewat nuansa warna yang menyusunnya. Dalam sebuah bukunya yang berjudul Tasteful Color Combination, seseorang bernama Naomi Kuno menyatakan bahwa suatu komposisi yang tersusun dari beberapa warna bisa memberikan nuansa tersendiri dan tentu memiliki karakteristik yang khas.

\section{Karakter Sebagai Suatu Media}

Dalam menciptakan karakter, seorang ilustrator terkadang menggunakan stereotype yang sekarang berkembang di masyarakat untuk menjadikan patokan standar bentuk tampilam karakter. Dalam animasi pembuatan karakter manusia, stereotype bisa diterima dengan baik oleh para penonton melalui penggambaran karakter yang diasosiasikan bersama profesi karakter tersebut. Hal ini tentu dapat menjadi sebuah ikon yang bisa digunakan sebagai bagian dari suatu cerita dalam bentuk visual. Karakter tertentu seperti manusia, dapat dikenali dengan baik lewat penampilan fisiknya. Stereotype juga dapat dirasakan melalui benda-benda yang biasa digunakan oleh karakter. Benda-benda tersebut juga hadir sebagai simbol dari karakteristik tertentu (Eisner, 2008).

\section{Analisis Karakter Tokoh Utama Animasi Pocoyo}

Pocoyo adalah animasi yang mengisahkan seorang anak balita berpakaian warna biru yang penuh dengan rasa ingin tahu dengan segala sesuatu yang ada di sekitarnya. Bentuk visual karakter tokoh utama yang dihadirkan dalam dunia tiga dimensi, dengan menggunakan background yang berwarna putih saja. Karakter utama merupakan karakter yang selalu dan sering muncul dalam setiap episodenya, dan Pocoyo ini adalah karakter utamanya. Berikut Analasis pada karakter Pocoyo sebagai tokoh utama:

1. Ekspresi Wajah Pocoyo

Pocoyo merupakan satu-satunya karakter manusia yang memiliki ekspresi wajah dan gesture, hal tersebut menunjukan bahwa karakter ini memiliki sifat yang ekspresif.

2. Penampilan dan Aksesoris Pocoyo

Bentuk penampilan dari karakter Pocoyo ini berupa seorang anak balita berumur empat tahun. Pocoyo memiliki bermacam benda-benda seperti kereta api mainan serta balok bangunan.

3. Bentuk dan Gestur Tubuh Pocoyo

Seperti yang terlihat dari benda-benda yang dimiliki Pocoyo, yang berarti Pocoyo memiliki kepribadian seperti anak balita yang ada pada umumnya yang aktif dan gemar bermain dengan mainan yang dimilikinya tersebut. 


\section{Warna dan Komposisi}

Pakaian yang digunakan Pocoyo memiliki warna biru yang memiliki kaitan dengan kebudayaan barat yang cenderung berpikir warna biru merupakan identitas gender laki-laki.

Di animasi Pocoyo juga terdapat karakter-karater pendukung yang juga muncul sebagai teman dari tokoh utama, antara lain adalah Pato, Elly, Loula, dan Sleepy Bird. Karakter-karakter ini tidak muncul sesering tokoh utama yang selalu ada di setiap episode. Namun, penggarap animasi ini tetap menerapkan prinsip desain karakter pada semua karakter pendukung seperti karakter utama.

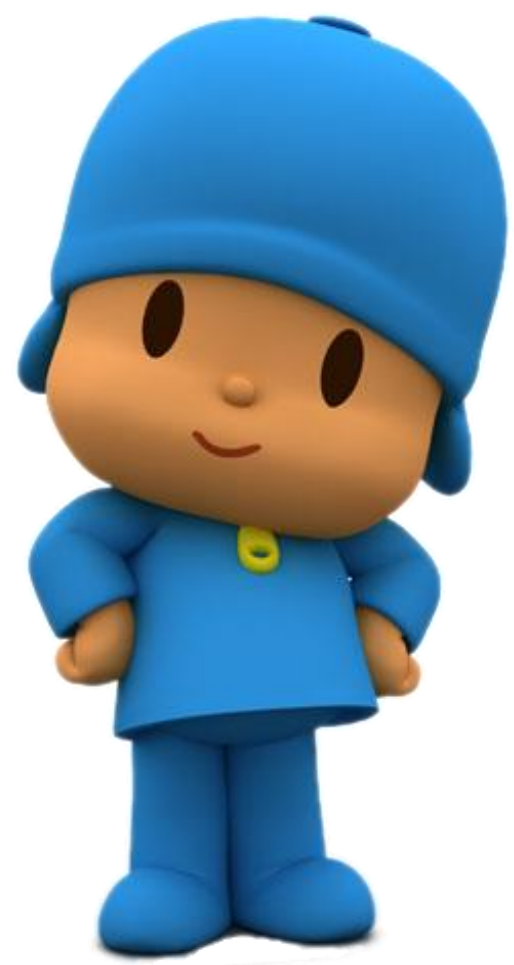

Gambar 4. Karakter tokoh utama animasi Pocoyo

Sumber: http://pocoyo.blogs.com/.

\section{SIMPULAN}

Dengan menerapkan prinsip desain karakter, Animasi Pocoyo berhasil mengekplorasi karakter tokoh utama yang ada agar kepribadian karakter yang disampaikan kepada penonton dapat tersampaikan dengan baik. Ekspresinya, benda yang selalu dibawa, warnanya, benar-benar bisa mendapatkan konsentrasi yang optimal sehingga tanpa bantuan adanya bermacam latar belakang pun karakter tersebut bisa menarik perhatian penonton. Dari Animasi Pocoyo dapat disimpulkan bahwa suatu karakter tidak harus tampil bagus dan keren, karakter yang terlihat sederhana namun memiliki unsur-unsur yang penuh makna dapat hadir sebagai karakter yang baik seperti yang ada pada animasi Pocoyo.

\section{DAFTAR PUSTAKA}

Eisner, W. (2008). Graphic storytelling and visual narrative: principles and practices from the legendary cartoonist ; In A Will Eisner instructional book CN - Ku 879.Eis 12.

Pococo.com (2019). Pococo. http://pocoyo.blogs.com/.

Rachmat, R. (2017). Desain Karakter. Jakarta: ITB.

Shinugi, B. (2009). Membuat Karakter. Bandung: Mediantara Semesta. 
Syahfitri, Y. (2011). Teknik film animasi dalam dunia komputer. Journal Saintikom, 10 (3), 213 217 